\title{
A SAÚDE PÚBLICA ENQUANTO DEVER DO ESTADO: O REPASSE DESTE DEVER À SAÚDE SUPLEMENTAR
}

Public health as the State's duty: the handing over of this duty to supplementary health

${ }^{1}$ Universidade Regional do Noroeste do Estado do Rio Grande do Sul. Ijuí/RS, Brasil. Correspondência: Janaína Machado Sturza. E-mail: janasturza@hotmail.com.

Recebido em: 22/11/2016. Revisado: 14/02/2017. Revisado novamente: 25/05/2017. Aprovado: 19/06/2017. 


\section{RESUMO}

A presente análise jurisprudencial busca fomentar a discussão acerca do dever do Estado de prestar saúde pública, apresentado na Constituição Federal de 1988, frente à saúde suplementar. Nessa perspectiva, vislumbram-se o surgimento da saúde suplementar e os deveres vinculados aos contratos antigos e aos firmados após sua regulamentação. Este debate, portanto, é norteado pelo método dedutivo a partir de uma abordagem bibliográfica. Restou analisada a transferência de responsabilidade por meio do procedimento administrativo denominado de "Ressarcimento ao Sistema Único de Saúde". Nesse cenário, apontam-se algumas considerações quanto à temática com base na jurisprudência do Tribunal do Estado do Rio Grande do Sul, do Superior Tribunal de Justiça e Supremo Tribunal Federal.

\section{Palavras-Chave}

Direito à Saúde; Saúde Pública; Saúde Suplementar.

\section{ABSTRACT}

This jurisprudential analysis seeks to foster a discussion about the State's duty to provide public health, presented in the 1988 Federal Constitution, confronting supplementary health. In this perspective, are glimpsed the advent of supplementary health and the obligations linked to the old contracts and the contracts signed after its regulation. Therefore, this debate is guided by a deductive method, from a bibliographical approach. The transfer of responsibility was analyzed through an administrative procedure called Reimbursement to SUS. In this scenario, some considerations on the subject are pointed out based on the jurisprudence of the Court of Justice of the State of Rio Grande do Sul, Brazilian Superior Court of Justice and Brazilian Supreme Court.

\section{Keywords}

Public Health; Right to Health; Supplementary Health. 


\section{Introdução}

Visa o presente texto a debater acerca da ascendência do direito à saúde, correlacionada com a concentração dos deveres atribuídos ao Estado e o surgimento dos planos de saúde suplementar. Pretende-se, de igual forma, explanar a transmissão de responsabilidade existente entre a saúde pública e a saúde suplementar, bem como os mecanismos existentes para ressarcimento entre elas, contrapondo-os com a fundamentação jurisprudencial nas demandas de prestação da saúde e suas divergências.

Este estudo se faz necessário uma vez que a consolidação do acesso à Justiça, conjuntamente com a exímia evolução tecnológica no setor médico-hospitalar e a evidente decadência da economia nacional, resta por confirmar o fenômeno da “judicialização da saúde”. Não se constata unanimidade na Justiça sobre as condições estabelecidas nos contratos firmados antes da publicação da Lei n. 9.656/1998, ou na vigência desta (como o rol de procedimentos da Agência Nacional da Saúde Suplementar - ANS), e não se observa que a tomada de decisão pelo julgador tenha como base as notórias constatações médico-científicas.

Nesses termos, ocorre certa confusão em relação a quem deve prestar a assistência à saúde, tanto por parte dos consumidores - que não sabem quais os limites contratuais do serviço suplementar firmado - quanto por parte das operadoras de planos de saúde - que ficam à mercê de decisão judicial sobre como melhor proceder ao pedido de atendimento.

Além disso, ocorre no meio administrativo o procedimento de ressarcimento promovido pelo Sistema Único de Saúde (SUS) em desfavor das operadoras de saúde suplementar, visando a rever custos ocorridos por beneficiários de planos de saúdes na rede pública de assistência. O referido procedimento é objeto de processo judicial, que hoje aguarda julgamento no Supremo Tribunal Federal, uma vez que foi declarado como de "repercussão geral".

Neste estudo, foi possível analisar os aspectos constitucionais do direito à saúde no Brasil, em especial no que comporta o dever do Estado nesta prestação, contrapondo o surgimento da saúde suplementar e as feições jurisprudenciais na concessão de tutela de obrigação de atendimento. E, ainda, verificaram-se os principais aspectos jurídicos-constitucionais fundamentadores do direito à saúde e sua aplicabilidade nos processos judiciais.

\section{Do entendimento jurisprudencial}

Discutir a jurisprudência tem sido a mais eficiente forma de entender o direito, já que a doutrina e a legislação são aplicadas aos casos do cotidiano da sociedade. Ademais, a jurisprudência tem se consagrado como fonte principal do direito. Nesse sentido, explica-se: 
A jurisprudência é a fonte mais geral e extensa de exegese, indica soluções adequadas às necessidades sociais, evita que uma questão doutrinária fique eternamente aberta e dê margem a novas demandas: portanto diminui os litígios, reduz ao mínimo os inconvenientes da incerteza do Direito, porque de antemão faz saber qual será o resultado das controvérsias ${ }^{1}$.

A jurisprudência indica as soluções mais adequadas à sociedade, evitando que questões da doutrina perdurem em discussões sem resolução em vista. Portanto, no que se refere a essa dualidade de entendimentos apresentada pela saúde suplementar e pela saúde pública, é de vasta importância observar o que vem sendo expressado pela jurisprudência, uma vez que propõe soluções aos casos concretos dessa relação de sistemas.

\section{Das decisões judiciais quanto ao dever do Estado}

Primeiramente são colacionados julgados quanto à saúde pública e à chamada prestação universal do direito à saúde, independentemente da complexidade e do tipo do evento médico solicitado, com o fim de comprovar que o dever do Estado é incondicional a todos. Assim, inicialmente, verificam-se decisões que apresentam o entendimento majoritário do Tribunal de Justiça do Estado do Rio Grande do Sul (TJRS), demonstrado pelo seguinte:

APELAÇÃO CÍVEL. DIREITO PÚBLICO NÃO ESPECIFICADO. FORNECIMENTO DE MEDICAMENTOS. GARANTIA CONSTITUCIONAL DOS DIREITOS À SAÚDE E À VIDA. INTELIGÊNCIA DOS ARTS. 196 DA CF E 241 DA CE. PARECER TÉCNICO DA SES. MEDICAMENTO OFF LABEL. MEDICAMENTO NÃO INDICADO PARA O CID DA PATOLOGIA EM APREÇO. EFICÁCIA DO FÁRMACO.

A Carta Magna erigiu a saúde como sendo direito de todos e dever do Estado, nos termos dos arts. 196, da CF e 241, da CE, portanto, inconteste a obrigação do Estado, independentemente de qual seja a esfera de poder, em virtude da competência comum, conforme o disposto no art. 23, II, da CF.

Não prospera a improcedência da ação tendo por argumento que o tratamento é experimental e, portanto, sem comprovação de sua eficácia para o CID da patologia em tela, porquanto o ato de diagnosticar patologias e receitar medicamentos/tratamentos ou dizê-los inadequados a este ou aquele diagnóstico compete muito mais ao médico da paciente. Destarte, embora possua

${ }^{1}$ RODIGHERI, André. Jurisprudência como fonte do direito. Âmbito Jurídico, Rio Grande, v. 7, n. 17, maio 2004. Disponível em: <http://www.ambito-juridico.com.br/site/index.php?n_link=revista_artigos_leitura\&artigo_ id=3965 > . Acesso em: 23 maio 2016. 
caráter experimental, não se pode dizer que não seja eficaz ao tratamento da parte autora. APELAÇÃO DESPROVIDA. UNÂNIME. (TJRS, Apelação Cível n. 70069247799, Segunda Câmara Cível, Relator: João Barcelos de Souza Junior, Julgado em $25 / 05 / 2016)^{2}$. (Destaques nossos.)

O caso em comento cuida de uma solicitação de fornecimento de medicamento que, conforme entendimento do Estado, tratava-se de assistência médica experimental, uma vez que o medicamento solicitado foi categorizado como off label - ou seja para uso diferente do indicado na bula. A referida decisão baseou-se na garantia constitucional do direito à vida aliada ao apresentado no artigo 196 da Constituição Federal de $1988^{3}$ (CF/88), que define o direito a saúde como sendo destinado a todos e dever do Estado - uma vez que, conforme afirma o relator da ação em seu voto "demonstrada a gravidade das doenças e não podendo a parte autora custear os medicamentos, cabe ao ente público o fornecimento dos fármacos imprescindíveis à sua vida"

Inclui-se ainda outro julgado do TJRS, o qual confirma a tese quanto o dever do Estado:

APELAÇÃO CÍVEL. DIREITO HUMANO À SAÚDE. CIRURGIA BARIÁTRICA. RESPONSABILIDADE SOLIDÁRIA. DESPESAS PROCESSUAIS.

1. É responsabilidade do Estado (União, Estados, Distrito Federal e Municípios) fornecer atendimento cirúrgico aos que dele necessitam, na forma do que dispõem os artigos $196 \mathrm{da}$ Carta Magna e 241 da Constituição Estadual ao estabelecerem que a saúde é direito de todos e dever do Estado.

2. Comprovada a urgência no procedimento, não há que se falar em violação ao princípio da isonomia ou impossibilidade de sua realização de forma particular.

3. Declarada a inconstitucionalidade da Lei Estadual $n^{\circ}$ 13.471/2010 (Incidente de Inconstitucionalidade $\mathrm{n}^{\circ} 70041334053$ e ADI n 70038755864), aplica-se, portanto, a redação original do art. 11 do Regimento de Custas. As despesas processuais devem ser suportadas na integralidade, excetuadas as despesas de condução com Oficial de Justiça no caso do Estado. APELAÇÃO IMPROVIDA. (TJRS, Apelação Cível n. 70069028140, Quarta Câmara Cível, Relator: Francesco Conti, Julgado em 25/05/2016) ${ }^{4}$. (Destaques nossos.)

2TRIBUNAL DE JUSTIÇA DO ESTADO DO RIO GRANDE DO SUL. Apelação Cível N. 70069247799, Segunda Câmara Cível, Tribunal de Justiça do RS, Relator: João Barcelos de Souza Junior, Julgado em 25/05/2016. ${ }^{3}$ BRASIL. Constituição da República Federativa do Brasil de 1988. Disponível em: <http://www.planalto.gov. br/ccivil_03/constituicao/constituicaocompilado.htm>. Acesso em: 31 out. 2017.

${ }^{4}$ TRIBUNAL DE JUSTIÇA DO ESTADO DO RIO GRANDE DO SUL. Apelação Cível N 70069028140, Quarta Câmara Cível, Tribunal de Justiça do RS, Relator: Francesco Conti, Julgado em 25/05/2016. 
Assevera-se a importância de identificar decisões nas quais o atendimento restou prestado pelo SUS, independentemente de o paciente ter assegurado serviço de saúde suplementar contratado junto ao ente privado. Assim, colaciona-se outro julgado do Tribunal de Justiça do Estado do Rio Grande do Sul:

\begin{abstract}
APELAÇÃO CÍVEL. DIREITO HUMANO À SAÚDE. MEDICAMENTOS. CÂNCER. CACON. PLANO DE SAÚDE. UNIMED. 1.É responsabilidade do Estado (União, Estados, Distrito Federal e Municípios) o fornecimento de prestações necessárias à preservação da vida e da saúde - sem restrição às listas do SUS -, na forma do que dispõem os artigos 196 da Carta Magna e 241 da Constituição Estadual ao estabelecerem que a saúde é direito de todos e dever do Estado. A repartição de competência no Sistema Único de Saúde não afasta a responsabilidade solidária dos entes públicos, razão por que o Estado deve fornecer o medicamento pleiteado, malgrado os Centros de Alta Complexidade em Oncologia (CACONs) serem mantidos pela União. 2. O simples fato de a parte autora estar assegurada por plano de saúde que prevê a cobertura de tratamento oncológico não é suficiente para afastar o dever dos entes. (TJRS, Apelação Cível n. 70068350339, Quarta Câmara Cível, Relator: Francesco Conti, Julgado em 30/03/2016)5. (Destaques nossos.)
\end{abstract}

Conforme se vê decisão acima, o fato de existir a contratação de plano de saúde particular não significa um afastamento ou uma abdicação do direito constitucional à saúde pública. Portanto, trata-se de uma faculdade disponível ao cidadão de contratar serviço suplementar, porém não poderá o Estado deixar de prestar assistência por esse motivo. Ademais, é expresso na ementa:

[...] o simples fato de a parte autora estar assegurada por plano de saúde que prevê a cobertura de tratamento oncológico não é suficiente para afastar o dever dos entes públicos no fornecimento do tratamento de que necessita.

Aqui foi respeitada a negativa emitida pelo plano de saúde, uma vez que a referida foi analisada pela ANS, que confirmou a legitimidade da negativa.

\title{
1.2 Das decisões judiciais quanto aos planos de saúde
}

No que se refere ao dever das operadoras de planos de saúde, importa ressaltar a existência do debate quanto ao reconhecimento ou não da aplicabilidade da Lei dos Planos de Saúde aos contratos firmados em sua vigência e antes dela, e também quanto ao acolhimento nas decisões judiciais do rol restrito de cobertura

${ }^{5}$ TRIBUNAL DE JUSTIÇA DO ESTADO DO RIO GRANDE DO SUL. Apelação Cível No 70068350339, Quarta Câmara Cível, Tribunal de Justiça do RS, Relator: Francesco Conti, Julgado em 30/03/2016. 
presente nos contratos antigos, que por muitas vezes enfraquece a relação entre o consumidor e a operadora.

Nessa senda, primeiramente é vislumbrado um julgado expedido pelo TJRS, no qual foi analisada a aplicabilidade da Lei dos Planos de Saúde (Lei n. 9.656/19886) e o acolhimento ou não do rol restrito presente nos contratos antigos:

AÇÃO DE OBRIGAÇÃO DEFAZER. PLANO DE SAÚDE. RADIOTERAPIA IMRT. NEGATIVA DE COBERTURA. descabimento.

I. Nos termos do art. 14, do CPC/2015, a norma processual não retroagirá, respeitados os atos processuais praticados e as situações jurídicas consolidadas sob a vigência da norma revogada. Dessa forma, aplicam-se ao presente processo as disposições constantes do CPC/1973, em vigor quando do ajuizamento da ação, da prolação da sentença e da interposição do presente recurso.

II. No caso, a autora é portadora de câncer de colo de útero, necessitando realizar o tratamento de Radioterapia com a técnica de Intensidade Modulada do Feixe - IMRT, cuja cobertura foi negada pela operadora do plano de saúde.

III. Entretanto, os contratos de planos de saúde estão submetidos às normas do Código de Defesa do Consumidor, na forma da Súmula 469, do STJ, devendo ser interpretados de maneira mais favorável à parte mais fraca nesta relação. De outro lado, os planos de saúde apenas podem estabelecer para quais moléstias oferecerão cobertura, não lhes cabendo limitar o tipo de tratamento que será prescrito, incumbência essa que pertence ao profissional da medicina que assiste o paciente. Além do mais, deve ser priorizado o direito à saúde e à vida em relação ao direito contratual. Incidência dos arts. 47 e 51, IV, $\$ 1^{\circ}$, II, do CDC.

IV. Ademais, o tratamento de Radioterapia IMRT não está previsto nas hipóteses de exclusão do art. 10, da Lei no 9.656/98, a qual dispõe sobre os planos e seguros privados de assistência à saúde. De outro lado, embora a contratação original tenha sido anterior à entrada em vigor da Lei $\mathrm{n}^{\circ} 9.656 / 98$, tal diploma legal é perfeitamente aplicável à situação dos autos, haja vista que o contrato de plano de saúde, por ser de trato sucessivo, renova-se anual e automaticamente. V. Por conseguinte, a requerida deve arcar com o tratamento indicado à parte autora. APELAÇÃO DESPROVIDA. (TJRS, Apelação Cível n. 70066069378, Quinta Câmara Cível, Relator: Jorge André Pereira Gailhard, Julgado em 25/05/2016) ${ }^{7}$. (Destaques nossos.)

${ }^{6}$ BRASIL. Lei n. 9.656, de 3 de junho de 1988. Dispõe sobre os planos e seguros privados de assistência à saúde. Disponível em: <http://www.planalto.gov.br/ccivil_03/leis/L9656compilado.htm>. Acesso em: 31 out. 2017.

${ }^{7}$ TRIBUNAL DE JUSTIÇA DO RIO GRANDE DO SUL. Apelação Cível N. 70066069378, Quinta Câmara Cível, Tribunal de Justiça do RS, Relator: Jorge André Pereira Gailhard, Julgado em 25/05/2016. 
Giza-se que é entendimento do Supremo Tribunal Federal (STF) de que o disposto no Código de Defesa do Consumidor é perfeitamente aplicável aos planos de saúde, sendo razoável, portanto, a afirmação do relator da ação de que o "art. 47, do CDC, determina que as cláusulas contratuais serão interpretadas de maneira mais favorável ao consumidor". Logo, por se tratar de plano de saúde firmado antes da vigência da Lei dos Planos de Saúde ${ }^{8}$, resta provável a inexistência de cláusula restritiva do atendimento, tendo em vista que na época da contratação o referido tratamento sequer existia.

Ademais, se no contrato constasse cláusula que restringiria o atendimento, essa cláusula perderia a aplicabilidade, já que

é nula a cláusula que estabeleça obrigações consideradas iníquas, que coloquem o consumidor em desvantagem [...] restringe direitos ou obrigações inerentes à natureza do contrato, ameaçando seu objeto e equilíbrio, ou ainda que seja excessivamente onerosa ao consumidor. (Voto do relator.)

Portanto, o referido julgado não observa o Parecer Técnico n. 45/GEAS/ GGRAS/DIPRO/2016, emitido pela ANS, o qual indica as coberturas a serem observadas, mostrando que o Judiciário não considera a força normativa da regulamentação.

Quanto à aplicabilidade da Lei dos Planos de Saúde, expressa o julgador em seu voto:

[...] embora a contratação original tenha sido anterior à entrada em vigor da Lei n. 9.656/98, tal diploma legal é perfeitamente aplicável à situação dos autos, haja vista que o contrato de plano de saúde, por ser de trato sucessivo, renova-se anual e automaticamente.

Conforme supracitado, a Lei dos Planos de Saúde é aplicável a todos os contratos de planos de saúde, independentemente da data de sua contratação. Porém, tal entendimento mostra-se equivocado, uma vez que a própria lei expressa em seu artigo 35:

Art. 35. Aplicam-se as disposições desta Lei a todos os contratos celebrados a partir de sua vigência, assegurada aos consumidores com contratos anteriores, bem como àqueles com contratos celebrados entre 2 de setembro de 1998 e $1^{\circ}$ de janeiro de 1999 , a possibilidade de optar pela adaptação ao sistema previsto nesta Lei. (Destaques nossos.)

${ }^{8}$ BRASIL. Lei n. 9.656, de 3 de junho de 1988, cit.

${ }^{9}$ AGÊNCIA NACIONAL DE SAÚDE. Parecer técnico n. 45/GEAS/GGRAS/DIPRO/2016. Disponível em: <http:// www.ans.gov.br/images/stories/parecer_tecnico/uploads/parecer_tecnico/_parecer_2016_45.pdf>. Acesso em: 31 out. 2017. 
Assim, o julgado é contrário às determinações previstas na própria Lei dos Planos de Saúde sobre sua aplicação retroativa, ao passo que a própria regulamentação assegura aos consumidores a possibilidade de se adaptarem à lei através de um procedimento administrativo (o qual prevê adequação da mensalidade), e não de forma automática - e, assim, o enquadramento é errôneo quanto ao trato sucessivo.

Ainda, a referida negativa está de acordo com a Lei dos Planos de Saúde, sendo novamente equivocado indicar que o caso não está previsto nas hipóteses de exclusão do artigo 10 desta lei como suficiente para se proferir sua disponibilização, uma vez que deixaram de ser observados os termos constantes no rol de coberturas previsto na Resolução Normativa (RN) n. 387/2015 10 da ANS, cujo anexo I apresenta os procedimentos de cobertura obrigatória: Radioterapia com modulação da intensidade do feixe (IMRT) para tumores da região da cabeça e pescoço (destaques nossos).

Tendo em vista o acima exposto, resta assegurada a cobertura para casos nos quais o paciente apresenta tumor na região da cabeça e pescoço, o que diverge do caso do julgado.

Para assessorar o entendimento no que se refere à aplicabilidade do rol de coberturas previsto pela ANS, colacionamos outro julgado do TJRS, referente à concessão de medicamento quimioterápico domiciliar não previsto no rol de coberturas obrigatórias da Lei dos Planos de Saúde:

APELAÇÃO CÍVEL. SEGUROS. PLANO DE SAÚDE. NEGATIVA DE COBERTURA. AÇÃO DE OBRIGAÇÃO DE FAZER CUMULADA COM PEDIDO DE ANTECIPAÇÃO DE TUTELA. CÂNCER. INDICAÇÃO DO MEDICAMENTO VOTRIENT DE USO ORAL PARA TRATAMENTO QUIMIOTERÁPICO DOMICILIAR. COBERTURA DE VIDA. AUSÊNCIA DO ROL DA ANS QUE NÃO EXCLUI RESPONSABILIDADE DA OPERADORA DO PLANO DE SAÚDE DE COBRIR O TRATAMENTO. JURISPRUDÊNCIA DESTE TRIBUNAL E DO E STJ NEGARAM PROVIMENTO AO APELO. UNÂNIME. (TJRS, Apelação Cível n. 70069112845, Sexta Câmara Cível, Relator: Rinez da Trindade, Julgado em 12/05/2016) ${ }^{11}$. (Destaques nossos.)

\footnotetext{
${ }^{10}$ AGÊNCIA NACIONAL DE SAÚDE. Resolução normativa - RN n. 387, de 28 de outubro de 2015 Atualiza o Rol de Procedimentos e Eventos em Saúde, que constitui a referência básica para cobertura assistencial mínima nos planos privados de assistência à saúde, contratados a partir de $1^{\circ}$ de janeiro de 1999; fixa as diretrizes de atenção à saúde; revoga as Resoluções Normativas - RN n. 338, de 21 de outubro de 2013, RN n. 349, de 9 de maio de 2014; e da outras providências. Disponível em: <http://www.ans.gov.br/component/legislac ao/?view=legislacao\&task=TextoLei\&format=raw\&id=MzExMA==>. Acesso em: 31 out. 2017.

${ }^{11}$ TRIBUNAL DE JUSTIÇA DO RIO GRANDE DO SUL. Apelação Cível N. 70069112845, Sexta Câmara Cível, Tribunal de Justiça do RS, Relator: Rinez da Trindade, Julgado em 12/05/2016.
} 
No voto do relator do julgado acima, confirma a tese majoritária de que "o rol de coberturas obrigatórias da ANS diz respeito a coberturas mínimas, servindo apenas como orientador das prestadoras de serviços de saúde (destaques nossos). Destarte, não pode a apelante excluir ou limitar tratamento médico sem expressa previsão legal, não sendo razoável a recusa da cobertura, sob pena de desequilíbrio contratual" (destaques nossos). Portanto, independentemente da época da contratação, regulamentada ou não, "as cláusulas contratuais devem ser interpretadas de maneira mais favorável ao consumidor, nos termos do artigo 47 do Código de Defesa do Consumidor" (destaques nossos).

Conforme todo o referido, o artigo 35 da Lei dos Planos de Saúde, que vincula sua aplicabilidade apenas aos contratos firmados sob sua égide, não tem força frente ao Judiciário gaúcho: no primeiro caso, foi garantida sua aplicabilidade a todos os contratos, a partir da classificação como contratação de trato sucessivo; no primeiro e no segundo casos, no que se refere às exclusões de cobertura, é visível que, na ocorrência de negativa e se não indicado nos casos expressamente excluídos por lei, não poderá ter aplicação, uma vez que as cláusulas contratuais serão interpretadas de forma mais favorável ao beneficiário.

Por fim, no que se refere à intepretação baseada no Código de Defesa do Consumidor ${ }^{12}$, ressalta-se que essa tese é confirmada pelo Superior Tribunal de Justiça (STJ); porém, quanto à aplicabilidade da Lei dos Planos de Saúde, ocorre outro entendimento, conforme segue:

DIREITO CIVIL E CONSUMIDOR. SEGURO SAÚDE. CONTRATAÇÃO ANTERIOR À VIGÊNCIA DO CDC E À LEI 9.656/98. EXISTÊNCIA DE TRATO SUCESSIVO. INCIDÊNCIA DO CDC, MAS NÃO DA LEI 9.656/98. BOA-FÉ OBJETIVA. PRÓTESE NECESSÁRIA À CIRURGIA DE ANGIOPLASTIA. ILEGALIDADE DA EXCLUSÃO DE “STENTS" DA COBERTURA SECURITÁRIA. DANO MORAL CONFIGURADO. DEVER DE REPARAR OS DANOS MATERIAIS.

- As disposições da Lei 9.656/98 só se aplicam aos contratos celebrados a partir de sua vigência, bem como para os contratos que, celebrados anteriormente, foram adaptados para seu regime. A Lei 9.656/98 não retroage, entretanto, para atingir o contrato celebrado por segurados que, no exercício de sua liberdade de escolha, mantiveram seus planos antigos sem qualquer adaptação.

- Embora o CDC não retroaja para alcançar efeitos presentes e futuros de contratos celebrados anteriormente a sua vigência, a legislação consumerista regula os efeitos presentes de

${ }^{12}$ BRASIL. Lei n. 8.078, de 11 de setembro de 1990. Dispõe sobre a proteção do consumidor e dá outras providências. Disponível em: <http://www.planalto.gov.br/ccivil_03/leis/L8078.htm>. Acesso em: 31 out. 2017. 
contratos de trato sucessivo e que, por isso, foram renovados já no período de sua vigência.

- Dada a natureza de trato sucessivo do contrato de seguro saúde, o CDC rege as renovações que se deram sob sua vigência, não havendo que se falar aí em retroação da lei nova.

- A cláusula geral de boa-fé objetiva, implícita em nosso ordenamento antes da vigência do CDC e do CC/2002, mas explicitada a partir desses marcos legislativos, impõe deveres de conduta leal aos contratantes e funciona como um limite ao exercício abusivo de direitos.

- O direito subjetivo assegurado em contrato não pode ser exercido de forma a subtrair do negócio sua finalidade precípua. Assim, se determinado procedimento cirúrgico está incluído na cobertura securitária, não é legítimo exigir que o segurado se submeta a ele, mas não instale as próteses necessárias para a plena recuperação de sua saúde.

- É abusiva a cláusula contratual que exclui de cobertura a colocação de "stent", quando este é necessário ao bom êxito do procedimento cirúrgico coberto pelo plano de saúde. Precedentes. - Conquanto geralmente nos contratos o mero inadimplemento não seja causa para ocorrência de danos morais, a jurisprudência desta Corte vem reconhecendo o direito ao ressarcimento dos danos morais advindos da injusta recusa de cobertura de seguro saúde, pois tal fato agrava a situação de aflição psicológica e de angústia no espírito do segurado, uma vez que, ao pedir a autorização da seguradora, já se encontra em condição de dor, de abalo psicológico e com a saúde debilitada. (STJ, REsp 735.168/RJ, Terceira Turma, Relatora: Nancy Andrighi, Julgado em 11/03/2008, DJe $26 / 03 / 2008)^{13}$. (Destaques nossos.)

Conforme demonstrado, o STJ reconhece a aplicabilidade da Lei dos Planos de Saúde apenas aos contratos firmados sob a égide desta, demonstrando ser o mais razoável e de acordo com a legislação.

\subsection{Das decisões quanto à legalidade do ressarcimento ao SUS}

O ressarcimento ao SUS apresenta a principal discussão de legalidade no que se refere à relação entre o sistema público e a saúde suplementar, uma vez que não se sabem ao certo os limites existentes na responsabilidade atribuída à assistência privada em substituição ao Estado com dever irrestrito e irrevogável. Nessa senda, colacionamos o entendimento apresentado pelo Tribunal Regional Federal da $4^{\text {a }}$ Região (TRF4):

\footnotetext{
${ }^{13}$ SUPERIOR TRIBUNAL DE JUSTIÇA. REsp 735.168/RJ, Rel. Ministra NANCY ANDRIGHI, TERCEIRA TURMA, julgado em 11/03/2008, DJe 26/03/2008.
} 


\begin{abstract}
ADMINISTRATIVO E PROCESSUAL. RESSARCIMENTO AO SUS. ART. 32 DA LEI N. 9.656/98. CONSTITUCIONALIDADE. LEGALIDADE.
\end{abstract}

1. A Lei n. 9.656/98 foi promulgada com a finalidade de evitar o enriquecimento sem causa de operadoras privadas, quando seus associados recebem tratamento médico em instituições públicas. O valor que seria despendido por tais empresas acaba sendo debitado dos cofres públicos, gerando prejuízos sociais imensuráveis para aqueles que têm o direito constitucional à saúde, mas não podem arcar com os gastos dos serviços hospitalares privados. Nesse sentido é o artigo 32 da lei supracitada, por cuja constitucionalidade a Corte já se manifestou.

2. Sentença mantida. (TRF4, AC 5043717-23.2013.4.04.7000, Quarta Turma, Relatora: Salise Monteiro Sanchotene, juntado aos autos em 19/04/2016) ${ }^{14}$. (Destaques nossos.)

O referido julgado confirma o entendimento de que o ressarcimento é devido, uma vez que se configura o enriquecimento sem causa, nos termos observados pela doutrina, já que o valor que deixou de ser gasto pela saúde suplementar gera prejuízos aos cofres públicos, causando uma onerosidade excessiva a quem tem o dever irrestrito a cumprir.

No mesmo sentido, expressou o Tribunal Federal da 2a Região:

APELAÇÃO CIVIL. ADMINISTRATIVO. RESSARCIMENTO AO SUS. ART. 32 DA LEI No 9656/98. CONSTITUCIONALIDADE.

1. O artigo 32, da Lei $n^{\circ} 9.656 / 98$, que trata do ressarcimento ao Sistema Único de Saúde - SUS é constitucional, consoante a súmula $\mathrm{n}^{\circ} 51$ desta Corte.

2. Cumpre afastar a alegação de afronta aos arts. 196 e 199 da Constituição Federal, eis que a norma em questão em nada modifica a atuação obrigatória do Estado nas atividades inerentes à saúde pública, nem desautoriza a atuação das demais pessoas no âmbito privado, mas apenas impõe o ressarcimento pelo plano privado do atendimento prestado pela rede pública.

3. Inexiste violação do princípio da legalidade pela Resolução RDC 17, que criou a Tabela Única Nacional de Equivalência TUNEP, visto que cabe à ANS regulamentar, fiscalizar e controlar as ações e serviços de saúde, consoante o disposto no $\$ 7^{\circ}$, do art. 32, da Lei 9.656/98. A ANS estabeleceu as condições para o ressarcimento, bem como os valores que devem ser observados, respeitando-se a norma insculpida no $\$ 8^{\circ}$ do referido dispositivo, que determina que os valores a serem ressarcidos não devem ser

${ }^{14}$ TRIBUNAL REGIONAL FEDERAL DA 4 ${ }^{\mathrm{a}}$ REGIÃO. TRF4, AC 5043717-23.2013.4.04.7000, QUARTA TURMA, Relatora SALISE MONTEIRO SANCHOTENE, juntado aos autos em 19/04/2016. 
inferiores aos praticados pelo SUS e nem superiores aos praticados pelas operadoras de saúde, sendo que tais valores podem variar de acordo com as operadoras.

4. Não há que se cogitar da aplicação retroativa da Lei 9.656/98, porque ela não retroage para interferir na relação contratual, mas tão-somente incide gerando o dever da operadora de ressarcir a União pelos atendimentos prestados após o seu advento.

5. Deve ser afastada a nulidade das AIHs pelo fato da realização de serviços ocorrer fora da área de abrangência dos contratos, eis que o local da realização é indiferente, permanecendo a obrigação de ressarcimento ao SUS pelos serviços prestados, conforme entendimento no âmbito do Tribunal Regional Federal da $2^{\text {a }}$. Região.

6. Apelo desprovido. (TRF4, Processo 200751010318610, Oitava Turma Especializada, Relatora Marcelo Pereira da Silva, Publicação: 14/08/2017) ${ }^{15}$. (Destaques nossos.)

O julgado acima também apresenta o entendimento quanto ao dever de ressarcir ou não procedimentos não cobertos. Seu teor é de que a falta de cobertura expressa afasta o dever do ressarcimento, porém é indiferente quando ao local de realização do procedimento, não atendendo a abrangência local contratual prevista.

No STF, a referida questão restou reconhecida como caso de repercussão geral, tendo em vista seu impacto econômico e jurídico na sociedade brasileira: "Recurso Extraordinário. Administrativo. Ressarcimento ao Sistema Único de Saúde SUS das despesas com atendimento de pacientes beneficiários de planos privados de saúde. Art. 32 da Lei 9.656/1998. Repercussão geral reconhecida”16.

Nestes termos, apesar de a questão constitucional ter sido arguida pelo Supremo na ADI-MC 1931-8/DF ${ }^{17}$, verificou-se a necessidade de apreciar o tema devido aos inúmeros questionamentos não sanados. Dentre vários pontos, um que chama mais atenção é a questão da legalidade, já que a ANS não está vinculada ao Congresso Nacional. Portanto, a Agência tem dever regulador, e não de normatizar no campo autônomo do Direito, ainda mais em questão que envolve balizar o dever da legalidade, presente em um Estado Democrático de Direito.

Conforme todo o exposto, vê-se que a questão da constitucionalidade e legalidade do ressarcimento ao SUS ainda não possui uma definição final, tendo em vista o crescente questionamento e imposição de demandas dessa natureza. Assim, caberá ao Supremo dar seu parecer final e impor ou não tal dever à saúde suplementar.

\footnotetext{
${ }^{15}$ TRIBUNAL REGIONAL FEDERAL DA $4{ }^{\text {a }}$ REGIÃO. TRF4, AC 5043717-23.2013.4.04.7000, QUARTA TURMA, Relatora SALISE MONTEIRO SANCHOTENE, juntado aos autos em 19/04/2016.

${ }^{16}$ SUPREMO TRIBUNAL FEDERAL. RE 597064 RG, Relator(a): Min. GILMAR MENDES, julgado em 09/12/2010, DJe-058 DIVULG 28-03-2011 PUBLIC 29-03-2011 EMENT VOL-02491-02 PP-00331.

${ }^{17}$ SUPREMO TRIBUNAL FEDERAL. ADI 1931-8/DF, Relator: Ricardo Lewandowski, julgado em 02/03/2010.
} 


\section{Conclusão}

A prestação jurisdicional no que tange ao direito à saúde, por seu caráter fundamental, necessita de tratamento especial, não havendo fundamento passível para a negação de prestação assistencial. Assim, a interpretação dos termos da Carta Magna de 1988 pertinentes à prestação pública de saúde possibilita uma variedade de direitos conexos, não sendo possível prever as possibilidades futuras de concessão.

Portanto, entende-se ser justificável ajustar o entendimento jurídico-constitucional da concepção até então existente acerca do dever do Estado no cumprimento da saúde pública, bem como a responsabilidade obtida pelas operadoras de plano de saúde suplementar. Sem essa percepção, torna-se impraticável a aplicação do direto sanitário aos beneficiários da saúde privada e aos usuários da saúde púbica, pois a eles não é demonstrado um "limite", muitas vezes restando-lhes recorrer ao Judiciário para que este indique a existência ou não de seu direito.

Nesse sentido, para que não ocorra um desvirtuamento da concessão da saúde no âmbito público, resta ao Estado - que assumiu seu dever geral e irrestrito a todos os cidadãos brasileiros - investir na área de auditoria médica a fim de se utilizar de divergências médicas para optar por tratamentos de menor valor. Assim, quando nas solicitações médicas de alto custo for averiguado que outro tratamento de menor custo causa o mesmo efeito, haverá uma justificativa técnica, que também seria importante o Estado Juiz reconhecer.

No que se refere à jurisprudência, esta entende o direito constitucional à saúde como obrigação do Estado, geral e irrestrita a todos, não verificando a real necessidade ou a possibilidade de substituição do tratamento por outro menos oneroso - entendendo que o médico assistente tem autoridade sobre as questões de saúde do paciente. Porém, é valido passar a questionar indicações médicas que possam causar o colapso da saúde pública a fim de preservar a isonomia de concessão do Estado.

No caso da saúde suplementar, vislumbra-se ser apropriado que a Justiça brasileira, nos casos dos contratos firmados sob a égide da Lei dos Planos de Saúde, se valha da regulamentação e suas atualizações, uma vez que as operadoras são obrigadas a obedecer aos exatos termos de sua agência fiscalizadora. Isso afastaria ampla gama de processos judiciais que são interpostos em razão da dúvida da aplicabilidade dos termos da lei.

A jurisprudência entende que, quando a aplicação da lei especial pode desfavorecer o beneficiário, aplica-se o Código de Defesa do Consumidor, interpretando de forma mais favorável ao consumidor. Ademais, a Lei dos Planos de Saúde propõe coberturas obrigatórias, atualizadas a cada dois anos, as quais os julgados colacionados entendem como coberturas mínimas, excepcionando nas demandas judiciais sob o argumento de que as únicas exclusões válidas são as legalmente previstas. 
Aos contratos firmados antes da supracitada lei, a ANS possibilita a adaptação e/ou migração aos termos da regulamentação, tendo por contraprestação uma adequação de no máximo 20,59\% da mensalidade. Porém, a existência de dúvida quanto aos direitos provenientes da contratação outrora firmada faz com que os beneficiários sejam contrários ao procedimento de regulamentação de contrato.

Portanto, seria conveniente que os consumidores e as operadoras de planos de saúde promovessem uma revisão contratual, tendo em vista que os aspectos pertinentes à saúde no momento da contratação hoje restam arcaicos. Assim, observando-se a imprevisão novos aspectos, a execução da obrigação contratual não é possível nas mesmas condições pactuadas, o que leva a uma necessidade de exigibilidade diversa: a contratação é revisada de forma equânime, não restringindo direitos e verificando um ajuste financeiro realmente justo.

No que tange às contratações antigas, a jurisprudência tem aplicado o entendimento do contrato como trato sucessivo, ou seja, que se renova a cada ano. O TJRS atribui o dever de aplicar a Lei dos Planos de Saúde a tais contratos, porém tal entendimento não foi confirmado no juízo ad quem, que aplicou apenas o Código de Defesa do Consumidor.

Em relação ao ressarcimento ao SUS, a doutrina, apesar de indicar certa divergência quanto a sua legalidade, não diverge ao indicar que os custos não encaminhados à saúde suplementar causam onerosidade excessiva ao sistema público, que tem o dever geral de prestar a saúde e não possui condições financeiras para tanto. Porém, grande parte afirma (e também diverge) que, independentemente disso, o Estado tem um dever geral que deve cumprir, não sendo correto encaminhá-lo às empresas privadas.

Assevera-se que a jurisprudência, em sua intenção majoritária, compreende o ressarcimento como constitucional e devido, inclusive configurando-o como tributo, mas que ele deve figurar como ressarcimento por um possível enriquecimento sem causa. Já a Suprema Corte, apesar de ter julgado na ADI-MC 1931-8/DF o artigo que prevê legalmente o ressarcimento ao SUS e confirmado sua constitucionalidade, entendeu, após o surgimento de demais questionamentos, por determinar repercussão geral e demandar a questão para um julgamento futuro, baseado em seu possível impacto econômico, jurídico e social.

Tendo em vista o supracitado, é possível verificar que, independentemente desse impacto econômico, jurídico e social, é provável que a questão constitucional e legal não seja alterada, mantendo-se o procedimento de ressarcimento ao SUS. Porém, é importante indicar que, em razão da insegurança jurídica dos contratos de plano de saúde, é necessária uma melhor compreensão de quais os casos deverão ensejar tal reembolso para que o ressarcimento ao SUS tenha uma correta aplicação. 
Portanto, para que a saúde pública e a privada possam se relacionar de forma isonômica, sem que uma cumpra o dever da outra, necessita-se de uma melhor segurança jurídica nas contratações da saúde suplementar, bem como uma melhor compreensão por parte dos julgadores e dos demais membros da sociedade jurídica, para que não ocorram demandas judicias sem a devida razão. Assim, o SUS somente prestará aquilo que está devidamente excluído de cobertura por parte dos contratantes da saúde suplementar e a quem não possui qualquer vínculo com a saúde privada, sendo exclusivamente usuário da saúde pública.

Por outro lado, tendo o contrato devidamente firmado, a saúde suplementar manterá uma segurança jurídica e financeira, economizando com as demandas judiciais e prestando um serviço devidamente legal. Vale ressaltar que, para tanto, no momento da venda os fornecedores deverão ser claros quanto ao produto vendido, o que trará uma satisfação maior ao usuário.

Para que o saúde pública se sustente, é importante que o Estado reforce o investimento na saúde básica a fim de prevenir melhor as doenças e, consequentemente, reduzir custos, uma vez que não atende devidamente à população nos moldes atuais. Resta importante indicar que um sistema balizador talvez fosse importante, pois promoveria uma melhora no longo prazo, que ajustaria a economia brasileira da saúde e a própria saúde da população.

\section{Referências}

RODIGHERI, André. Jurisprudência como fonte do direito. Âmbito Jurídico, Rio Grande, v. 7, n. 17, maio 2004. Disponível em: <http://www.ambito-juridico.com.br/site/index. php?n_link=revista_artigos_leitura\&artigo_id=3965>. Acesso em: 23 maio 2016.

Janaína Machado Sturza - Doutora em Direito pela Uniroma III. Professora no Programa de Pós-Graduação em Direito - Mestrado da Universidade Regional do Noroeste do Estado do Rio Grande do Sul. Ijuí/RS, Brasil. E-mail: janasturza@hotmail.com.

Cassiano Vinícius dos Santos Beck - Graduando em Direito pela Universidade Regional do Noroeste do Estado do Rio Grande do Sul. Ijuí/RS, Brasil. 